\title{
EDUCAÇÃO PROFISSIONAL NO BRASIL: REFLEXÕES SOBRE DISCURSO POLÍTICO-EDUCACIONAL, CURRÍCULO E FORMAÇÃO TÉCNICA
}

\author{
PROFESSIONAL EDUCATION IN BRAZIL: REFLECTIONS ON POLITICAL- \\ EDUCATIONAL DISCOURSE, CURRICULUM AND TECHNICAL TRAINING
}

\author{
Rosália Maria Netto Prados ${ }^{1}$ \\ Senira Anie Ferraz Fernandez ${ }^{2}$
}

\section{Resumo}

A educação profissional brasileira na contemporaneidade contempla discursos que refletem sistemas de valores socioculturais e econômicos. O presente artigo discute o discurso que subjaz às políticas educacionais de modo a possibilitar algumas reflexões sobre Currículo e Formação Técnica. São objetivos, considerar concepções teóricas sobre educação profissional técnica, currículo, competências e habilidades, assim como descrever as relações interdiscursivas que perpassam práticas sociais e pedagógicas. A metodologia que orienta esta discussão, de abordagem qualitativa, é de estudos da linguagem na análise do discurso, enquanto percurso de produção de sentido, além de uma pesquisa descritiva que se baseia na reflexão teórica no âmbito da educação profissional. As discussões sobre o tema, qual seja, discurso político-educacional sobre o ensino profissional de nível médio, tomaram por universo empírico um currículo de Artes, de instituição pública de educação tecnológica. Os subsídios oferecidos pela semiótica tornaram possível a compreensão do processo discursivo político-educacional e das relações de linguagem pertinentes no que se refere à educação profissional e tecnológica.

Palavras-Chave: Educação Profissional; Currículo; Formação Técnica.

\begin{abstract}
\footnotetext{
${ }^{1}$ Universidade Mogi das Cruzes (UMC) - email: rosalia.prados@gmail.com

${ }^{2}$ Centro Estadual de Educação Tecnológica Paula Souza - email: digame@uol.com.br
}

Brazilian professional education in the contemporaneity includes discourses that reflect systems of socio-cultural and economic values. This article discusses the underlying speech to educational policies in order to allow some reflections on Curriculum and Technical Training. The objectives, to consider theoretical conceptions about technical professional education, curriculum, competences and abilities, as well as to describe the interdiscursive relations that perpass social and pedagogical practices. The methodology that guides this discussion, with a qualitative approach, is the study of language in discourse analysis, as a way of meaning production, as well as a descriptive research based on theoretical reflection in the field of professional education. The discussions on the subject, that is, political-educational discourse about the professional education of middle level, took by empirical universe an curriculum of 


\section{OD DEIR EDUCAÇÃO \\ ISSN: 2526-849X}

Arts, of public institution of technological education. The subsidies offered by semiotics have made possible the understanding of the political-educational discursive process and of the pertinent language relations in professional and technological education.

Keywords: Professional Education; Curriculum; Technical Training.

\section{Introdução}

Este estudo propõe uma análise do discurso político-educacional, no âmbito da educação profissional em nível técnico, e reflexões sobre o currículo e a formação integral do educando em um curso técnico de Artes. Os universos de discurso da ciência, técnica e tecnologias, que se manifestam no contexto das políticas da educação profissional, refletem os sistemas de valores socioculturais e econômicos contemporâneos. Neste sentido, aborda o modo pelo qual são percebidos, nas práticas sociais no campo da educação profissional, saberes, técnicas e tecnologias, a fim de se refletir sobre o currículo, competências e habilidades.

No atual contexto sociocultural, com o acelerado avanço de novas tecnologias, em que se caracterizam as exigências no mundo do trabalho, apresentam-se discursos políticoeducacionais e tecnológicos que definem práticas pedagógicas e formativas na educação profissional.

As inovações tecnológicas modificam o perfil do trabalho e do emprego, além de surgirem novos formatos de empresas e novas formas de gestão que são decorrentes do contexto globalizado contemporâneo. Tal fato, além do contexto histórico e social da educação profissional e tecnológica apresentado neste estudo, constituem um campo de tensões que suscitam discussões sobre a organização curricular. Para tanto recorre-se à análise do discurso, como interpretação do processo de produção de sentido.

Para esta análise de discurso da educação profissional no nível técnico, consideram-se os fundamentos teóricos em estudos da linguagem e da educação profissional. Na análise do discurso, consideram-se fundamentos semióticos. A Semiótica é considerada uma ciência da significação, já que, a aprendizagem de uma cultura, bem como, sua transmissão, conservação e transformação, realizam-se por meio de práticas sociais e respectivos processos discursivos (PRADOS; BONINI, 2017). Para Pais (1997), saber e significação articulam-se num processo de produção discursiva que refletem o sistema de valores de uma comunidade sociocultural e linguística.

Revista Devir Educação, Lavras, vol.2, n.2, p.90-100 jul./dez., 2018. 
Apresenta-se uma análise do discurso que se manifesta nos textos gerados no campo político-educacional da educação profissional de nível técnico que, no Brasil, orienta-se pelo Catálogo Nacional de Cursos Técnicos, cuja $3^{\text {a }}$ (terceira) edição foi publicada em 2016, pelo Ministério da Educação (MEC). Nesta análise propõe-se examinar as tensões discursivas que se estabelecem nas relações entre sujeitos envolvidos, no âmbito da educação profissional no nível técnico. São considerados nesse discurso, de acordo com as modalidades semióticas discursivas que, por sua vez ampliam o sentido que se dá às competências e habilidades, os sujeitos de um querer-saber, de um fazer-saber, de um saber-fazer e de um dever-ser/fazer na educação profissional tecnológica (PRADOS; BONINI, 2017).

Para este estudo, considera-se a educação em nível técnico que, não só atende a discursos político-educacionais, que existem para responder a diferentes demandas momentâneas, mas também para se criar um perfil de especificidades do ensino profissional contemporâneo brasileiro, como o da aplicação, desenvolvimento e produção de conhecimentos científicos inovadores e de sua relevância no contexto nacional.

São, portanto, objetivos deste trabalho: considerar concepções teóricas sobre educação profissional técnica, para a compreensão sobre o currículo, competências e habilidades; e descrever as relações intersubjetivas dos discursos da educação profissional, técnica e tecnológica, a fim de se refletir sobre as exigências contemporâneas do contexto sociocultural e econômico.

Assim, segundo a Semiótica, é possível reconstruir o processo discursivo no universo de discurso político-educacional e se considerar o estudo das relações de linguagem pertinentes para se discutir processos de construção do saber social e compartilhado, no que se refere à educação profissional e tecnológica.

\section{Discurso político-educacional e a educação profissional de nível técnico}

Ao se estudar a educação brasileira profissional e tecnológica, com frequência vem à lembrança o papel desempenhado pelo sistema jesuítico de educação durante o período colonial, sua catequese com práticas educativas de alguma forma ligadas ao trabalho. 
As noções de trabalho foram "se construindo e reconstruindo ao longo da história das sociedades humanas, variando de acordo com os modos de organização da população e de distribuição de riqueza e poder" (MANFREDI, 2002, p. 34). E, atualmente, as mudanças tecnológicas e organizacionais do trabalho em países capitalistas, a partir da década de 1980, configuraram o setor produtivo, a partir de algumas das características como, flexibilização da produção e reestruturação de ocupações; multifuncionalidade e polivalência dos trabalhadores; integração de setores da produção; valorização de saberes dos trabalhadores não ligados diretamente ao trabalho ou ao conhecimento formalizado e, nesse contexto, recupera-se um debate sobre a qualificação, segundo estudos sociológicos e pedagógicos (RAMOS, 2002).

Segundo Ramos (2002), a qualificação tem sido tensionada pela noção de competência, em razão do enfraquecimento de suas dimensões conceitual e social, ou seja, de sua função teórica e formalizada, associada a título ou diploma, ou no âmbito das relações sociais que se estabelecem entre conteúdo das atividades e classificação hierárquica, regras e direitos relativos ao exercício profissional construídos coletivamente.

Assim, a dimensão experimental da qualificação é que se sobressai e, para Ramos (2002), a noção de competência expressa coerentemente essa dimensão, já que é uma noção originária da Psicologia, em que se focam os atributos subjetivos mobilizados no trabalho. E, esse fenômeno tem um significado, não só técnico, mas também político, uma vez que em diferentes países foram reformulados sistemas de educação profissional, devido aos processos de globalização da economia e à crise do emprego, em que se fez necessária a criação de novos códigos para aproximar a educação das tendências produtivas.

A nova redação dada pela Lei n. ${ }^{\circ}$ 11.741/2008, nos artigos 39 e 42, definiu que a educação profissional e tecnológica "integra-se aos diferentes níveis e modalidades de educação e às dimensões do trabalho, da ciência e da tecnologia" (BRASIL, 2008a).

A expansão das redes de Educação Profissional, especialmente do ensino Técnico, deve-se à preocupação estatal em suprir uma qualificação de mão de obra, claramente em descompasso com as demandas do desenvolvimento do país, (PETEROSSI; MENINO, 2012).

Trabalho, mercado de trabalho, inovação, produtividade são dimensões presentes no ensino tecnológico. A especificidade das práticas da formação profissional é construída em outros ambientes para além do ambiente formal como sindicatos e empresas. 
$\mathrm{O}$ atual discurso político-educacional da educação profissional destaca-se no cenário nacional, a partir da Lei de Diretrizes e Bases da Educação Nacional (LDBEN) Nº 9394, de 20 de dezembro de 1996 (BRASIL, 1996). Quanto à discussão sobre a educação técnica, no contexto globalizado brasileiro, apresentam-se novos discursos e interpretações sobre saberes, competências e habilidades da educação profissional.

Para se refletir sobre o currículo de um curso técnico é necessário considerar o discurso político-educacional instaurado na legislação. No texto da LDBEN No 9394/96, foram incluídas novas regulamentações sobre a educação profissional de nível técnico que se apresenta na Seção IV-A, Da Educação Profissional Técnica de Nível Médio, incluída pela Lei $N^{\circ}$ 11.741, de 2008 (BRASIL, 2008a). E, considera-se que, no Inciso I, do Parágrafo Único, de seu Artigo 36B, está disposto que a educação profissional técnica de nível médio deve observar as diretrizes curriculares nacionais estabelecidas pelo Conselho Nacional de Educação.

A Portaria MEC N 870, de 16 de julho de 2008 (BRASIL, 2008b), tendo em vista o disposto no Capítulo III - Da Educação Profissional, da Lei no 9.394, de 20 de dezembro de 1996; no Art. $4^{\text {o }}$, do Decreto ${ }^{\circ}$ 5.154, de 23 de julho de 2004; no Parecer CNE/CEB no 11/2008 (BRASIL, 2008c); e na Resolução CNE/CEB nº 3, de 9 de julho de 2008 (BRASIL, 2008d); e a necessidade de se estabelecer um referencial comum às denominações dos cursos técnicos de nível médio, aprova o Catálogo Nacional de Cursos Técnicos de Nível Médio, elaborado pela Secretaria de Educação Profissional e Tecnológica do Ministério da Educação.

As Diretrizes Curriculares Nacionais para a Educação Profissional Técnica de nível médio, estabelecidas pelo Parecer CNE/CEB nº 11, de 2012 (BRASIL, 2012), consideram as transformações no mundo do trabalho, que promoveram uma mudança de eixo nas relações entre trabalho e educação, uma vez que a própria natureza do trabalho está passando por alterações profundas, considerando o avanço científico e tecnológico, além da mediação da microeletrônica. A Resolução CNE/CEB $\mathrm{N}^{\circ} 3$ de 2008, que teve como base o Parecer CNE/CEB n ${ }^{\circ} 11$ de 2008, tratou da constituição do Catálogo Nacional de Cursos Técnicos de nível médio, e em seu Artigo $3^{\circ}$ determina que os cursos constantes de tal Catálogo devessem ser organizados por eixos tecnológicos, definidores de um Projeto Pedagógico que contemple as trajetórias de um itinerário formativo e estabeleça as exigências profissionais que devem direcionar as ações educativas das instituições e sistemas educativos na oferta da Educação Profissional Técnica de nível médio.

Revista Devir Educação, Lavras, vol.2, n.2, p.90-100 jul./dez., 2018. 


\section{DEVIR EDUCAÇÃO \\ ISSN: 2526-849X}

A partir da década de 1990, segundo Tassigny (2008), a microeletrônica acarretou consequências importantes para o movimento de desqualificação e de qualificação da força de trabalho, ou quanto às exigências educacionais. $\mathrm{O}$ discurso do desenvolvimento de competências e habilidades passa a se configurar no universo educacional. Isso passou a fazer sentido, porque essa mudança da base eletromecânica para a base microeletrônica passou a exigir o desenvolvimento de certas habilidades cognitivas e comportamentais, como a capacidade de análise, síntese, rapidez de respostas, criatividade perante situações inesperadas, interpretação e uso de diferentes linguagens, ou ainda, capacidade para trabalhar em grupo.

Este estudo traz questões relevantes para se pensar competências e habilidades no contexto da Educação Profissional, em que se faz necessária uma reflexão sobre o processo e não somente voltada ao produto final, ou seja, sobre o conteúdo, objetivos e estratégias, mas no sentido pleno da formação humana. Os cursos técnicos de nível médio, portanto, têm por finalidade o desenvolvimento de competências profissionais que permitam tanto a correta utilização e aplicação de determinada tecnologia, bem como o desenvolvimento de novas aplicações, ou adaptação a novas situações profissionais, além do entendimento das implicações daí decorrentes e de suas relações com o processo produtivo e sociedade.

São necessárias, também, cada vez mais, novas formas de organização do currículo, a fim de que seja possível uma formação integral, para atender às exigências de um contexto de crescente disseminação da informação e do conhecimento. E as competências, portanto, constituem um conjunto de conhecimentos, atitudes, capacidades e aptidões que habilitam a certos desempenhos.

Pensar o currículo no ensino técnico é considerar a constituição de valores sobre educação e trabalho, não só para o exercício profissional e da cidadania, mas também para aperfeiçoar o próprio campo tecnológico.

Ao se considerar o contexto sociocultural da educação profissional, por meio da análise semiótica, pode-se refletir sobre o currículo, competências e habilidades. Um discurso, segundo Pais (1997a), é decorrente dos discursos que o antecederam e a produção discursiva só ocorre quando são utilizados signos e significações que possam ser interpretadas pelos demais membros de um mesmo grupo, ou seja, só será inteligível aos outros apenas quando se traduz em termos de consenso desse grupo.

Revista Devir Educação, Lavras, vol.2, n.2, p.90-100 jul./dez., 2018. 


\section{ODEVIR EDUCAÇÃO \\ ISSN: 2526-849X}

Para uma melhor compreensão do campo de estudo da Semiótica, é necessário considerar a capacidade de linguagem do ser humano, que se comunica por meio de sistemas de signos que, por sua vez, estão disponíveis para a atualização - processo que permite trazer um signo, dos bancos de memória, para uma situação nova, discurso manifestado em uma linguagem (PRADOS; BONINI, 2017).

Para Pais (1997a), os discursos pertencentes a um universo de discurso qualquer, ou do campo discursivo político-educacional apresenta características comuns, ou seja, constantes que configuram normas que produzem sentido em tal discurso, bem como, processos de produção de ideologia, ou sistema de valores, de relações intertextuais e interdiscursivas. Os discursos produzidos nas práticas socioculturais, desta maneira, apresentam estruturas caracterizadas pela persuasão, manipulação e sedução, que podem ser descritas como combinatórias de modalidades (PAIS, 1997b).

Por exemplo, um discurso político-educacional, que se manifesta em textos legais, produz sentido e, segundo a metodologia semiótica, pode ser descrito como: poder-fazerquerer $\rightarrow$ poder-fazer-saber $\rightarrow$ poder-fazer-dever. De acordo com os modelos de análise semiótica, na produção da significação do discurso político-educacional, apresenta-se uma vontade política, que pode ser descrita por um poder-fazer-querer, que por sua vez, instaura um sujeito de um querer e produz um sujeito de um saber e de um dever.

Assim, um universo de discurso como o político-educacional, manifestado, por exemplo, no texto do Parecer $\mathrm{n}^{\circ} 11$, de 2012, das Diretrizes Curriculares Nacionais para a Educação Profissional Técnica de nível médio, em que se produzem sentidos, de acordo com o contexto de relações educação X trabalho, instaura sujeitos e relações interdiscursivas. Traz o resultado de um fazer persuasivo de um sujeito destinador (Educação) e do fazer interpretativo de um sujeito destinatário (sociedade brasileira). Dessa maneira, evidencia-se que é no discurso que os sujeitos são construídos, ou seja, nesse percurso do sentido que a significação se produz.

Para se entender a metodologia semiótica discursiva, deve-se considerar a lógica aristotélica sobre forças ou tendências contrárias, dialeticamente articuladas. E a significação, enquanto função semiótica, sustenta-se numa tensão dialética entre termos contrários e contraditórios. Formaliza-se, então, a partir dessas relações entre os termos contrários e seus termos contraditórios e de outras relações que delas decorrem, um modelo descritivo semiótico dialético - que é um modelo de análise semiótica.

Revista Devir Educação, Lavras, vol.2, n.2, p.90-100 jul./dez., 2018. 


\section{Q DEVIR EDUCAÇÃO \\ ISSN: 2526-849X}

Um sistema de significação, como o da educação profissional técnica de nível médio, deve ser considerado como uma instância do processo semiótico de produção, de acordo com uma concepção dialética de sistema e estrutura, uma visão ampla e dinâmica.

Segundo Pais (1997b), todos os processos semióticos (sistemas X discursos) são determinados num percurso histórico-cultural e delimitados geograficamente, pois a visão de mundo de uma comunidade sociocultural e linguística, bem como sua ideologia e sistema de valores, encontra-se sempre em processo de atualização, (re)formulação e um constante modo de vir a ser que transmite a seus membros o sentido paradoxal de estabilidade e continuidade, ou seja, são processos culturais apreendidos no convívio social e trazem valores construídos historicamente.

\section{Currículo de artes e discurso político educacional da educação profissional: reflexões e análises}

Ao se considerar o discurso político-educacional sobre o ensino profissional de nível médio, foi tomado um currículo de Artes, de uma instituição pública de educação tecnológica. Os cursos técnicos em Artes estão inseridos no eixo tecnológico "Produção Cultural e Design" do Catálogo Nacional de Cursos Técnicos de nível médio (BRASIL, 2016). Na instituição estudada, são oferecidos os cursos: Arte Dramática; Canto; Dança; Design de Interiores; Eventos; Paisagismo; Processos Fotográficos; Regência, Composição e Arranjos; Produção Cultural.

Foi considerado, para esta discussão, como exemplo, o currículo do curso Técnico em Design de Interiores. O currículo do curso foi organizado em três módulos de quinhentas horas.

O Catálogo (BRASIL, 2016) define o perfil do profissional que conclui o curso, bem como o campo de atuação deste, além de apresentar a infraestrutura mínima exigida para a instituição, ocupações associadas, possibilidades de certificações intermediárias e de verticalização, para cursos de graduação tecnológica.

Esse discurso político-educacional manifestado sobre o ensino profissional técnico de nível médio, com base na metodologia semiótica, sustenta-se numa estrutura de poder que se 


\section{QO DEVIR EDUCAÇÃO \\ ISSN: 2526-849X}

define como um poder-fazer-querer $\rightarrow$ poder-fazer-saber $\rightarrow$ poder-fazer-dever. Há uma vontade política, ou seja, um poder-fazer-querer, para se adquirir um conhecimento, definido pelo poder-fazer-saber, a fim de que se instaure um dever.

Assim, a partir de instaurado um sujeito do querer (e do dever), esse discurso está subjacente aos textos educacionais e pedagógicos. Sustenta-se, portanto, nas modalidades: do poder-fazer-saber (conhecimento), para o poder-saber-fazer (competência), para o poderfazer-querer (vocação), para o poder-fazer-dever (ética), para o poder-fazer-crer (sistema de crenças), que produzem os efeitos de sentido da persuasão, manipulação e sedução no campo educacional e pedagógico.

No discurso político-educacional manifestado no contexto contemporâneo da educação profissional, entre os discursos presentes, dos quais os sujeitos se apropriam, está o discurso de uma nova Educação que deve atender às exigências do avanço tecnológico, que se opõe a uma Educação superior tradicional. Evidencia-se, portanto, que esse discurso políticoeducacional de uma educação profissional e tecnológica contemporânea se opõe a um outro discurso, o da educação tradicional, que se mantém por meio de valores socioculturais sobre a formação de nível médio.

Considere-se, aqui, que segundo Ramos (2002), nos documentos oficiais da educação profissional, a competência é descrita como ações específicas constituidoras das atividades profissionais, ou subfunções, e no plano cognitivo, procedimentos e esquemas mentais tornam-se a mesma coisa e permanecem exclusivamente como inteligência prática.

Desta maneira, possibilitar a discussão sobre os saberes necessários para a formação é um esforço que deveria se realizar continuamente, de modo que fosse possível perceber a pertinência de determinado currículo por competências diante das reais necessidades da sociedade.

\section{Considerações finais}

Em determinados momentos históricos do país, compreendeu-se a necessidade de habilitar técnica, social e ideologicamente diferentes grupos sociais para o trabalho, com a finalidade de responder às necessidades do bem econômico aplicável à produção. Ressalte-se, 


\section{OD DEIR EDUCAÇÃO \\ ISSN: 2526-849X}

assim, a ideia de que o desenvolvimento da educação profissional está diretamente ligado à formação educacional de um povo.

O estudo das estruturas dos discursos, segundo a Semiótica, tornou possível a reconstrução do sentido e a definição das modalidades que caracterizam as estruturas de poder do discurso político-educacional tecnológico, que produzem os efeitos de sentido nos discursos. Apresentam-se, portanto, sistemas de valores que se manifestam nos discursos e práticas sociais contemporâneas no campo da educação superior profissional e tecnológica. Desse modo são valores que constituem esse universo de discurso da educação profissional técnica de nível médio no Brasil.

Apresenta-se um discurso da ética, ou seja, do dever-ser/fazer e o do dever-nãoser/fazer, que se constitui a partir do discurso da vontade política que apresenta valores do contexto sociocultural e histórico que caracterizam o discurso político-educacional, atualmente, no universo da educação profissional técnica.

Atualmente, os discursos na Educação tratam da importância do saber numa sociedade globalizada, em que os avanços tecnológicos deixam em evidência a necessidade de se pensar mudanças no paradigma da produção do conhecimento, bem como da necessidade da (res)significação constante da educação profissional.

\section{Referências}

BRASIL. Lei 9.394, de 20 de dezembro de 1996. Lei de Diretrizes e Bases da Educação Nacional. Brasília, DF,1996. Disponível em: 〈http://portal.mec.gov.br/arquivos/pdf/ldb.pdf〉. Acesso em 22.mai.2015.

BRASIL. Lei No 11.741. de 16 de julho de 2008 (2008a). Brasilia, DF, 2008. Disponível em: < http://www.planalto.gov.br/ccivil_03/_Ato2007-2010/2008/Lei/L11741.htm> Acesso em 16.ago.2018.

BRASIL. Portaria MEC $\mathbf{N}^{\mathbf{0}}$ 870. Publicado em 18 de julho de 2008 (2008b). Brasília,DF,Disponível em:< http://pesquisa.in.gov.br/imprensa/jsp/visualiza/index.jsp?jornal=1\&pagina= $\underline{13 \& \text { data }=18 / 07 / 2008}>$ Acesso em 18.ago.2018. 
BRASIL. Parecer CNE/CEB n ${ }^{\circ}$. Catálogo Nacional de Cursos Técnicos de Nível Médio, 2008 (2008c). Brasília,DF.Disponível em: http://portal.mec.gov.br/setec/arquivos/pdf/pceb011_08.pdf $>$ Acesso em 14.ago.2018.

BRASIL. Resolução CNE/CEB no 3, de 9 de julho de 2008 (2008d). Brasília, DF.Disponível em: < http://portal.mec.gov.br/setec/arquivos/pdf/pceb011_08.pdf > Acesso em 12.ago.2018.

BRASIL. Parecer CNE/CEB $n^{\circ} 11$. Diretrizes Curriculares Nacionais para a Educação Profissional Técnica de Nível Médio, 2012. Brasília,DF. Disponível em: http://portal.mec.gov.br/index.php?option=com_docman\&view=download\&alias=10804pceb011-12-pdf\&category_slug=maio-2012-pdf\&Itemid=30192 Acesso em 03.set.2018.

BRASIL, Ministério da Educação. Catálogo Nacional de Cursos Técnicos de Nível Médio. $3^{\mathrm{a}} \quad$ edição.Brasília,DF, 2016. Disponível em: http://portal.mec.gov.br/index.php?option=com_docman\&view=download\&alias=41271cnct-3-edicao-pdf\&category_slug=maio-2016-pdf\&Itemid=30192> acesso em 03/09/2018.

MANFREDI, S. M. Educação profissional no Brasil. São Paulo: Cortez, 2002.

MENINO, S. E.; PETEROSSI, H. G.; FERNANDEZ, S. A. F. Desafios do processo de inovação. Revista Sinergia. IFSP, São Paulo, v. 12, p. 109-116, 2011.

PAIS, C.T. Conceptualização, denominação, designação: relações In: Revista Brasileira de Linguística. V. 9. Plêiade. São Paulo, p. 221-240, 1997a.

Texto, Discurso e Universo de discurso. In: Revista Brasileira de Linguística. v.8. Global. São Paulo, 1997b.

PRADOS, R. M. N.; BONINI, L. M. M. Ensaios de Semiótica Aplicada. Curitiba: Editora CRV, 2017.

RAMOS, M. N. A Educação profissional pela pedagogia das competências e a superfície dos documentos oficiais. In: Revista Educação e Sociedade. Campinas, vol. 23, n. 80, p. 401422, set.2002. Disponível em: < http://www.cedes.unicamp.br> Acesso em 24.ago.2018.

TASSIGNY, M. M. Revista Iberoamericana de Educación. № 48/1, 15 de diciembre de 2008. Madri, Espanha: Organización de Estados Iberoamericanos para la Educación, la Ciencia y la Cultura-OEI. Disponível em: <http://www.rieoei.org/deloslectores/2670TassignyMaq.pdf > Acesso em 15.out.2014. 